\title{
Tumor testicular bilateral "quemado" ("burn out")
}

\author{
M.J. Mola Arizo, V. Gonzalvo Pérez, M.D. Torregrosa Maicas*, J.A. Navarro Antón, \\ A. Gómez-Ferrer Lozano, A. Estany Pérez**, A.C. Polo Peris
}

Servicios de Urología, *Oncología y **Radiodiagnóstico del Hospital Lluis Alcanyis de Xàtiva. Valencia.

Actas Urol Esp 2005; 29 (3): 318-321

\section{RESUMEN}

TUMOR TESTICULAR BILATERAL “QUUEMADO” (“BURN OUT”).

Es difícil diferenciar entre tumor de células germinales retroperitoneal primario y enfermedad metastásica de un tumor gonadal indetectado o que ha regresado espontáneamente. Presentamos un caso clínico de "burn out" o tumor quemado, es decir un tumor retroperitoneal seminomatoso, metastásico con importantes alteraciones testiculares bilaterales tanto ecográficas como anatomopatológicas, pero sin evidenciar tumor. Pese a las controversias que detallamos, nuestra opción terapéutica fue la extirpación de la masa residual tras la quimioterapia asociada a orquiectomía bilateral en el mismo acto. Concluimos que ante un tumor retroperitoneal, la existencia de alteraciones ecográficas en los testículos, pese a una palpación normal, debe hacer pensar en un "Sindrome de burn out", siendo obligatoria la biopsia testicular bilateral. La exploración quirúrgica de los mismos e incluso la orquiectomía son opciones a valorar en función de cada paciente.

Palabras clave: Tumor testicular bilateral. Masa retroperitoneal. Orquiectomía.

\section{ABSTRACT \\ BURN OUT BILATERAL TESTICULAR TUMOR}

Differentiating a primary retroperitoneal seminoma from a metastatic testicular tumor with an occult testicular primary or a burned out testicular cancer remains difficult. We present a case of a burned out tumor. The patient had a retroperitoneal seminoma with ultrasonically and pathologically demonstrated abnormalities in both testes, but without evidence of tumor. The patient received chemotherapy and underwent surgery of the residual retroperitoneal mass and bilateral orchiectomy. All surgical specimens were negative for testis cancer. Conclusion: Primary extragonadal germ cell tumors in the retroperitoneum are a rare entity. The presence of a retroperitoneal tumor with ultrasonographical abnormalities in testicular evaluation should be considered as a metastases of a burned out testicular cancer, and biopsy is mandatory. Surgical evaluation and orchiectomy should be evaluated in a individual setting.

Keywords: Bilateral testicular tumor. Retroperitoneal mass. Orchiectomy.

$\mathrm{A}$ menudo es dificil diferenciar entre tumor de células germinales retroperitoneal primario y enfermedad metastásica de un tumor gonadal indetectado o que ha regresado espontáneamente, incluso algunos autores dudan de la existencia de verdaderos tumores retroperitoneales primarios de células germinales. Sin embargo, conside- ramos que la distinción entre ambos origenes del tumor, es fundamental ya que conlleva importantes diferencias tanto en el tratamiento, como sobre todo en el pronóstico de estos tumores.

Presentamos un caso clínico en el que pensamos se trata de un fenómeno de "burn out" o tumor quemado, es decir un tumor retroperitoneal 
seminomatoso, pero de origen testicular, pese a que no encontramos tumor en el estudio anatomopatológico de las gónadas, pero si importantes alteraciones tanto ecográficas como anatomopatológicas en ambos testículos.

\section{CASO CLÍNICO}

Varón de 33 años, sin antecedentes médicos ni quirúrgicos de interés que ingresa desde urgencias en la sala de traumatología con el diagnostico de lumbalgia rebelde al tratamiento domiciliario.

Se realizo TAC abdominopélvico en el que se aprecia gran masa retroperitoneal (paraaórtica) que se continua con la cadena iliaca primitiva y las cadenas iliacas, sobre todo la externa en el lado izquierdo de la cavidad abdominopelviana (9¥28 cm). La tumoración es sólida con pequeñas áreas de necrosis (Fig. 1). El TAC cervicotorácico fue normal.

Se practicó punción biopsia de la masa siendo el resultado anatomopatológico de tumor de células germinales tipo seminoma.

La exploración testicular bilateral fue normal y la ecografia testicular informó de múltiples imágenes ecogénicas puntiformes en ambos testículos (mas llamativas y extensas en el teste izquierdo), pero sin masa clara (Fig. 2a y 2b). Ante estos hallazgos ecográficos, se practicó biopsia testicular bilateral. En ambos testes la biopsia informó de atrofia testicular con patrón de síndrome de "solo células de Sertoli", hialinización tubular y microlitiasis.

En la analitica de sangre practicada al paciente llamaba la atención una LDH de 1903 y b-HCG de 23,8 , con $\alpha$-fetoproteína normal.

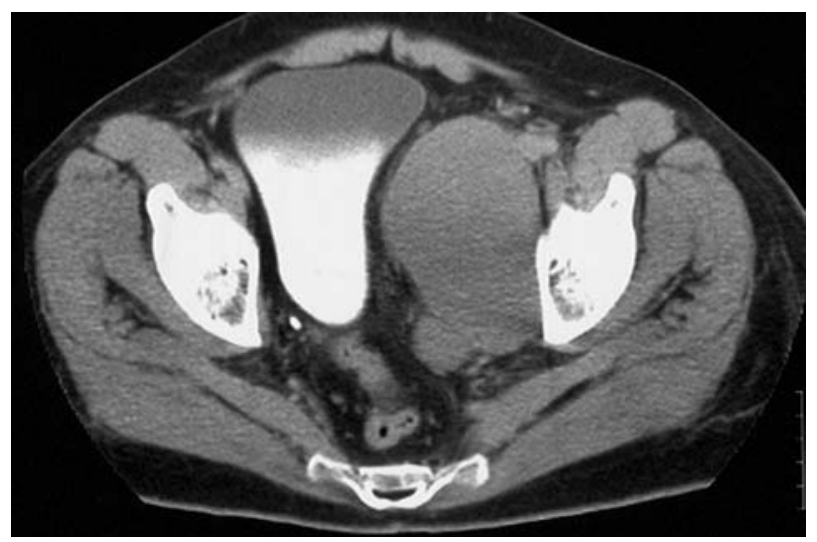

FIGURA 1
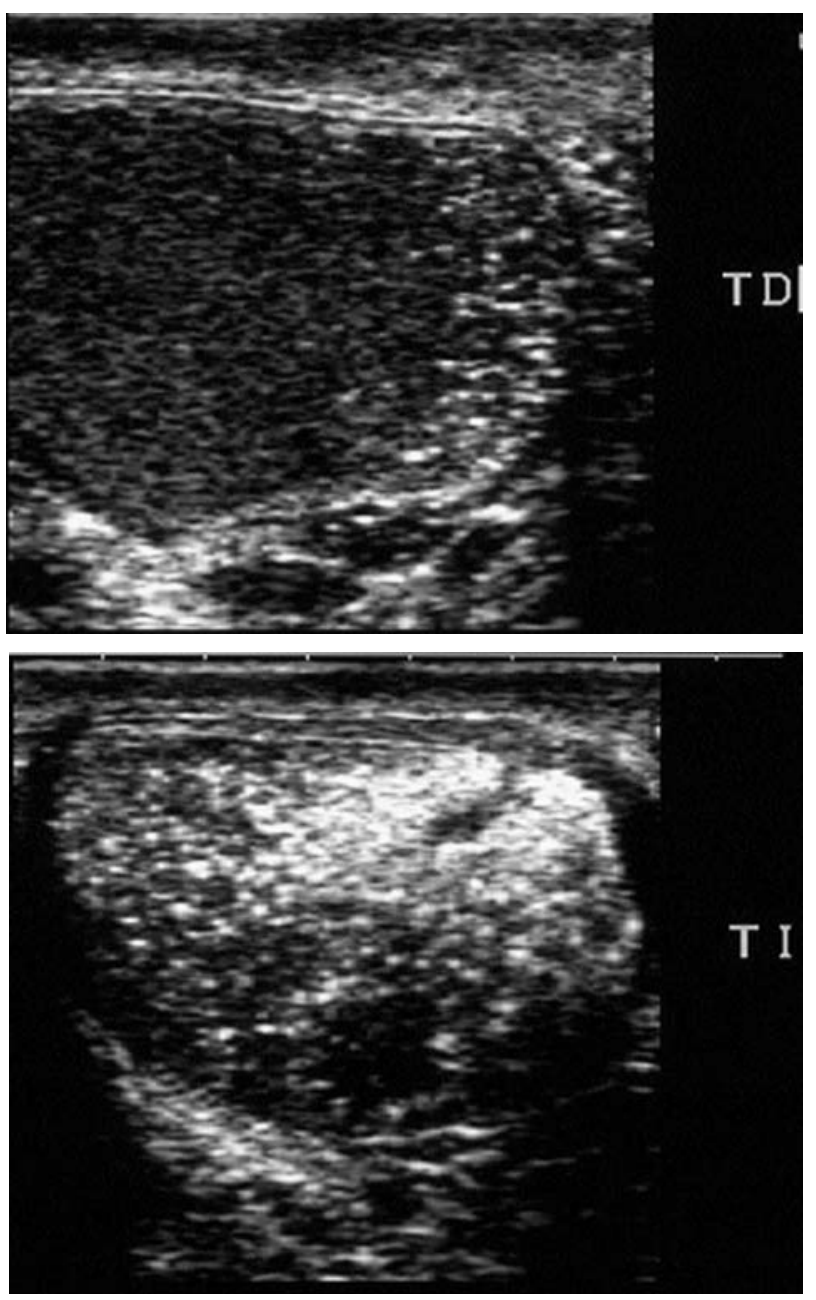

FIGURA $2 a$ y $2 b$

$\mathrm{El}$ paciente inició tratamiento con quimioterapia CTEP (Cisplatino y Etopósido). Después de 4 ciclos se practicó TAC de control, observándose la total desaparición de la masa retroperitoneal, quedando tan solo dos adenopatías paraaórticas izquierdas y otra en cadena iliaca izquierda de aproximadamente $3 \mathrm{~cm}$ cada una, por lo que el paciente recibió dos ciclos mas de CTEP, sin conseguirse reducción en el tamaño de dichas adenopatías (Fig. 3a y 3b).

Con la intención de extirpar la masa tumoral restante tras la quimioterapia, se practicó laparotomía media con resección de las adenopatías y orquiectomía bilateral. El estudio de las adenopatías informó de tejido fibroso con infiltrado linfoide disperso y necrosis sin observarse tumor. El estudio anatomopatológico de los testículos informo de síndrome de solo células de Sertoli, con importante atrofia tubular, hialinosis, calcificaciones y microlitiasis sin observarse tumor. 

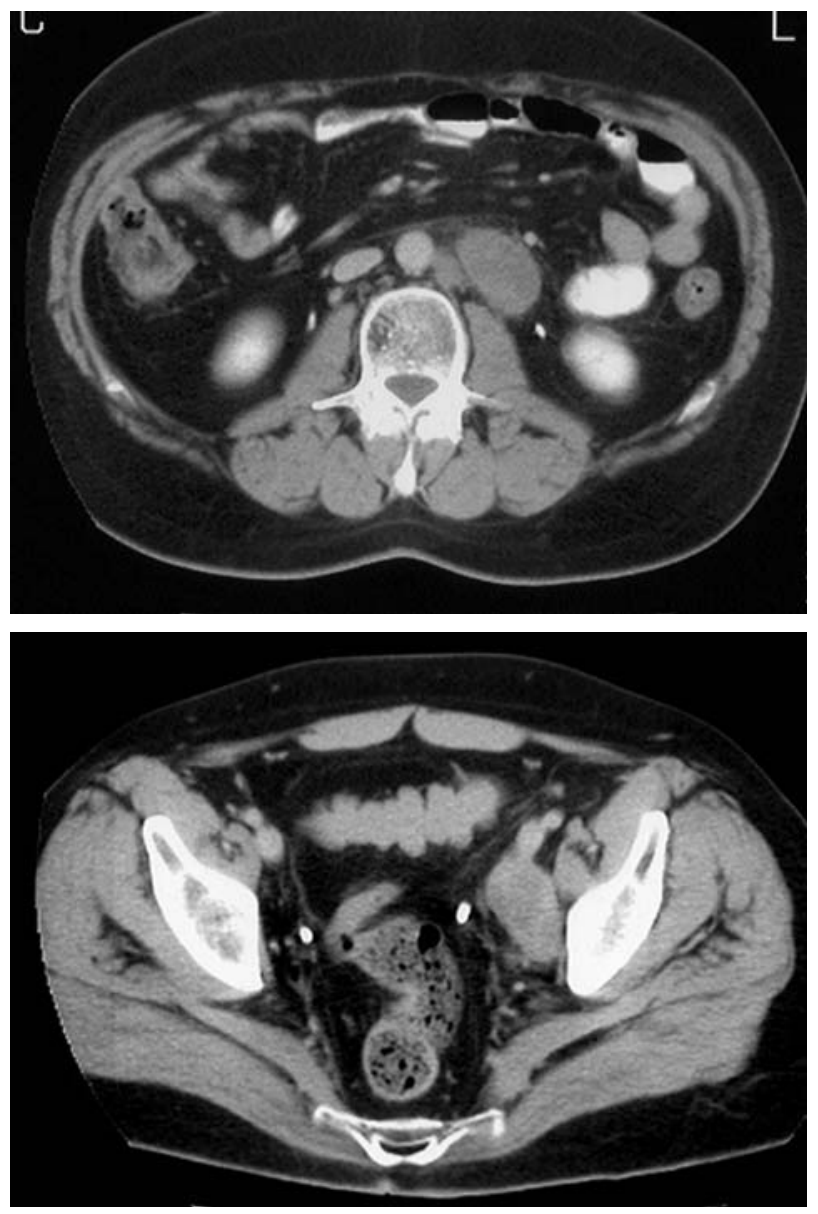

FIGURA $3 a$ y $3 b$

Tras doce meses de seguimiento, el paciente está clínicamente asintomático con tratamiento hormonal sustitutivo y sin recidiva radiológica ni analítica.

\section{DISCUSIÓN}

La idea de que un tumor testicular primario podía regresar o "quemarse" fue bien establecida en 1965 por Azzopardi y Hoffbrand ${ }^{1}$. Postularon que podía haber regresión de la lesión testicular primaria, que aparecería como una cicatriz en el parénquima testicular.

Existen revisiones recientes que concluyen que los llamados tumores extragonadales primarios son muy raros o prácticamente inexistentes y que en realidad en la mayoría de los casos se trata de metástasis de tumores bien viables o bien quemados ("burned out") en los testículos, dado que el 76\% de los pacientes presentan hallazgos patológicos en las biopsias testiculares $^{2}$.
En nuestro caso, la distribución de la masa retroperitoneal siguiendo las cadenas linfáticas así como la ecografía testicular y la biopsia de los mismos, nos hizo pensar desde el primer momento que estábamos ante un fenómeno de "burned out", aunque en este caso bilateral.

Dada la ausencia de tumor en la biopsia testicular se opto de entrada por la reducción de masa tumoral retroperitoneal con la quimioterapia, posponiendo la orquiectomía.

Ante la presencia de masa tumoral residual tras la quimioterapia decidimos la laparotomía, aprovechando el mismo acto quirúrgico para la orquiectomía bilateral.

Tal vez la orquiectomía bilateral pueda ser una opción controvertida, pero la mayoría de los autores recomiendan la orquiectomía del teste ipsilateral en el caso de que la ecografía revele alguna anormalidad incluyendo no solo la evidencia de tumor sino también calcificaciones intratesticulares o atrofia ${ }^{2-4}$. Lesiones hipo o hiperecoicas o microcalcificaciones han sido definidas como sospechosas de tumor testicular activo o bien "quemado" 2 . En este caso ambos testículos presentaban alteraciones ecográficas consistentes en microcalcificaciones y parénquima heterogéneo, pese a la palpación normal. De otra parte ambos testículos según la biopsia eran afuncionales tanto germinal como hormonalmente.

La existencia de "CIS" residual en los testículos después de la quimioterapia que ha destruido las metástasis a distancia, está bien documenta$\mathrm{da}^{5}$, pese a lo cual el estudio anatomopatológico de los testículos en nuestro caso, no reveló la existencia de tumor.

\section{CONCLUSIONES}

Los tumores primarios de células germinales en retroperitoneo, son muy poco frecuentes e incluso muchos autores dudan de su existencia ${ }^{6}$.

Ante un tumor retroperitoneal, la existencia de alteraciones ecográficas en los testículos, pese a una palpación normal, debe hacer pensar en un "Síndrome de burn out".

La biopsia testicular bilateral es obligatoria en los pacientes con tumor retroperitoneal de células germinales, ya que en prácticamente el 100\% de los casos, los hallazgos serán patológicos y en el $76 \%$ de los pacientes hay tumor viable o cicatrices ${ }^{2}$. 
La posibilidad de que quede tumor viable en los testículos tras la quimioterapia (santuarios) esta claramente demostrada, por lo que la exploración quirúrgica de los mismos e incluso la orquiectomía son opciones a valorar en función de cada paciente.

\section{REFERENCIAS}

1. Azzopardi JG, Hoffbrand AV. Retrogression in testicular seminoma with viable metastases. J Clin Pathol 1965;18:135-141.

2. Scholz M, Zehender M, Thalmann M et al. Extragonadal retroperitoneal germ cell tumor: evidence of origin in the testis. Annals of Oncology 2002;13:121-124.

3. Ojea Calvo A, Rodríguez Alonso D, Pérez García F, et al.: Tumor extragonadal de células germinales con fenómeno "burned-out" en testículo. Actas Urol Esp 1999;23(10):880884 .
4. Daniel C, Fizazi K, Culine S, et al.: Metachronous gonadal and extragonadal primaries, or late relapse of germ cell tumor?.Urologyc Oncology 2001;6:49-52.

5. Daugaard G, Rorth M, Von der Maase H, Skakkebak NE: Management of extragonadal germ-cell tumors and the significance of bilateral testicular biopsies. Annals of Oncology 1992;3:283-289.

6. Anglade RE, Chang B, Siroky MB: Primary retroperitoneal seminoma with ultrasonically abnormal testes. Urology 2001;57: 800i-800iii.

Dra. M.J. Mola Arizo

Hospital Lluis Alcanyis

Ctra. Xátiva-Silla, Km. 2

46800 Xátiva (Valencia)

(Trabajo recibido el 13 julio de 2004) 